\title{
Monks as Model Men: Gender Anomalies or Heroic Ideal?
}

\author{
Aaron Thomas Raverty ${ }^{1,2}$ \\ ${ }^{1}$ Saint John's Abbey, Collegeville, Minnesota, USA \\ ${ }^{2}$ Collegeville Institute for Ecumenical and Cultural Research, Collegeville, Minnesota, USA \\ Email: araverty@csbsju.edu
}

How to cite this paper: Raverty, A.T (2017) Monks as Model Men: Gender Anomalies or Heroic Ideal? Open Journal of Social Sciences, 5, 103-112.

https://doi.org/10.4236/jss.2017.56009

Received: April 9, 2017

Accepted: June 12, 2017

Published: June 15, 2017

Copyright (c) 2017 by author and Scientific Research Publishing Inc. This work is licensed under the Creative Commons Attribution International License (CC BY 4.0).

http://creativecommons.org/licenses/by/4.0/

\begin{abstract}
The movie The Mask You Live In portrays gender socialization for men in the United States today as dominated by a trajectory emphasizing ruthless competition, a never-ending search for prestige in material wealth, and a largely self-serving quest to overcome and control women. The movie graphically depicts all the accompanying psychological dysfunction, legal difficulties, and emotional distress experienced by boys and young men desperately trying to conform to such a scripted model of masculinity. Anthropological research invites alternate ways of thinking about the relationship between sex and gender. This is especially true among those who claim a close relationship with the supernatural or transcendent. Can the methodology of cultural anthropology provisionally expand the consideration of gender variants to provide other ways of modeling masculinity without discarding the underlying gender binary altogether? Catholic Christian monastics - men and women who commit to communal devotional and service roles in the light of transcendent aims and ends-demonstrate the potential for providing healthier alternative masculinity scripts. More specifically, can monks successfully model and communicate such an alternative masculinity for men in a higher educational institutional setting?
\end{abstract}

\section{Keywords}

Anthropology, Gender Variant, Masculinity, Monastics, Monks

\section{Introduction}

The movie The Mask You Live In is a powerful statement of how men are enculturated in Western societies. It uncovers a trajectory of masculine development that we largely take for granted, even though many of us men have been unwittingly deeply scarred by its message of a manly identity painfully gained at 
the expense of striving for competitive goals (especially as exemplified by sports and professional life), the unrelenting pursuit of material wealth, and the denigration of women, an identity frequently marked by anxiety, depression, and conflicted emotions. A very different movie, Two Spirits, tells the story of a gentle, young Native American Navajo man who discovers a very different gender trajectory because he comes to realize that he is same-sex attracted-or "two spirit": gifted in a uniquely spiritual way according to Navajo traditions-who finally pays the ultimate price at the hands of men socialized according to the "straight" model held up to them as "real men" in a manly world.

These two movies-The Mask You Live In and Two Spirits-differ from one another by depicting competing views of masculine gender identity and socialization. The Mask You Live In lays out the heteronormative, but largely dysfunctional, masculine script dominant in Western societies today. Two Spirits sets forth an ethnic gender variant masculinity not only tolerated by other members of the movie's Native American Navajo cultural group as an alternative to their heterosexual masculine ideal, but even welcomed and celebrated by them as a less common and special marker of exceptional artistic and spiritual gifts.

Gender has become a hot-button item as revealed in a recent issue of National Geographic Magazine (January 2017) entirely devoted to this topic. One of the aims of this issue, it seems, is to address the broad spectrum of current views and related practices of sex and gender in a sample of human societies around the globe. Such issues will be explored in this paper under the following headings: 1) sex versus gender, 2) gender categories, 3) methodological considerations, 4) gender and racial construction, 5) rethinking and revamping gender education, and 6) conclusion.

\section{Sex versus Gender}

The terms sex and gender are commonly used interchangeably today. Because the discipline of anthropology explores humanity through both a biological and a cultural lens, the distinction between sex and gender remains theoretically and methodologically crucial in constructing conceptual frameworks and isolating variables for hypothesis-testing (Walker, P.L. and Cook, D.C. 1998: 255) [1]. Eckert and McConnell-Ginet (2003: 10) [2] give us a succinct definition of gender as distinct from sex: "Gender is the social elaboration of biological sex": " $[\mathrm{T}]$ here is gender identity (sense of self), gender socialization (how people are expected to act) and gender expression (how a person dresses or styles their hair and so on)" (Steinmetz, K. 2017: 52) [3]. Accordingly, one can think of gender as a constellation of learned behaviors developmentally generated, duly internalized, and uniquely expressed around an individual's given biological sex.

Masculinity consists of an assemblage of both internalized and expressed attributes-material, behavioral, emotional, and linguistic-comprising the social elaboration characteristic of individuals of the male sex enculturated in a particular sociocultural setting or ethnic group. The acquisition of these masculine attributes may be conscious or unconscious. Examples of such expressive 
attributes may include-but are not limited to-clothing, technology, forms of speech and vocabulary choices, bodily comportment, occupation, and recreational outlets.

Cross-cultural research on shamans corroborates this sex/gender distinction. Harvey and Wallis (2007: 250) [4] have pointed out that, indeed, some "have challenged the Western binary "male or female" requirement, in which sex and gender are usually synonymous and heterosexuality is presumed to be normative. Far from being universal, these categories are disrupted by shamans who may embody a third or other multiple gender-without reference to sexuality". Bacigalupo, whose extensive fieldwork experience focused on the gender of religious agents, laments the fact that "a crucial aspect of the anthropology of shamanism and studies of gender, sexuality, and personhood... to date remains unexplored and undertheorized" (2007: 8) [5]. Even bioarcheologists like Sabrina Agarwal who are trying to reconstruct gender from archeological deposits of skeletal remains and associated artifacts recognize this problem. In an article in American Anthropologist, she comments: "Grouping individuals on the basis of sex has the effect of creating an a priori social group, a gender, based on selected biological features. A focus on the identity of a biologically determined group, such as 'woman', can erase significant variability within that category that comes from intersecting variables" (Agarwal, S.C. 2012: 324) [6].

\section{Gender Categories}

In her book Gender Diversity: Crosscultural Variations, anthropologist Serena Nanda invites us to consider the spectrum of gender categories among Native Americans. "There were many variations on North American Indian gender diversity. American Indian cultures included three or four genders: men, women, male variants, and female variants..." (Nanda, S. 2000: 13) [7]. For example, traditionally, the Native American Navajo recognized four genders: masculine man = hastin "man man"; feminine woman = asdzaan "woman woman"; feminine man = nadleehi "woman man"; and masculine woman = dilbaa "man woman." Thus we can speak of masculinity as an idealized gender script (such as heteronormativity) internalized and pursued by the male majority in any society, as well as alternatives on this normative ideal (gender variance) that deviate from it as internalized and expressed by male subgroups. In her book Men as Women, Women as Men: Changing Gender in Native American Cultures [8], Sabine Lang also discusses gender variance among Indian cultures. She rightly exposes the limitations and distortions of the classical term berdache for describing such variance associated with homosexuality, and introduces and elaborates the categories of "woman-man," and "man-woman" as more accurate and meaningful alternatives.

While such gender variants (i.e., woman-man and man-woman) shared, by and large, the occupational roles and activities of the more mainstream heteronormative masculine and feminine members, they were often accorded a special status, in which they excelled in such roles as matchmakers and religious spe- 
cialists, and especially as healers. They were sometimes sought out by other members of the native community for their unique skills and for what was considered their possession of exceptional spiritual gifts. In his classic ethnography, E. Adamson Hoebel (1978) [9] discusses such half men/half women among the Cheyennes.

Rethinking gender in this way, both Serena Nanda and Sabine Lang have prompted me to reconsider the masculine gender status of the Benedictine monks in the midst of whom I have had the opportunity to live these past forty-plus years of my own monastic life. My reconsideration of the masculinity of monks has encouraged me to look at "female monks"-more conventionally known as Benedictine nuns-as well, and to address issues of gender variance I have encountered in the process of many years of community immersion and concomitant participant observation.

To be a person is not merely to be embodied but to inhabit a public place. Our social selves are created for us, not just symbolically but also physically, within roles determined by social, cultural, and religious hierarchies and by gender stereotypes. So, for example, we put on our masculinity or femininity along with our clothes and manners so as to change the very shape our bodies occupy in place (Sheldrake, P. 2001: 56) [10].

My own research among these populations coupled with a literature search has prompted me to propose a hypothesis relating gender and the sacred: The more closely deities, religious specialists, and persons of great holiness are associated with the transcendent and/or sacred in any cultural worldview, the greater their drift toward gender variance. Although it requires further substantiation, my suspicion is that, in such a context, the performative aspect of heteronormative gender fades into the background, while a greater variety (lability?) of gender expression becomes tolerated and foregrounded-in some cases, perhaps, even encouraged. It is as if the numinous quality with which such individuals are presumably imbued frees them from the requirement to adhere to and express their culturally defined gender script in straightforward and unambiguous ways. Siberian, Andean, Middle Eastern, Ancient Near Eastern, (East) Indian, Philippine, and other Native American ethnographic sources all attest to the gender variance associated with sacred or supernatural entities (Czaplicka, M. 1914 [11]; Balzer, M.M. 1996: 175 [12]; Horswell, M.J. 2005: 17 [13]; Launderville, D. 2010: 316-317 [14]; Peletz, M.G. 2006 [15], 2009 [16]; Peled, I. 2016 [17]). As mentioned earlier, shamans seem to be especially vulnerable to such gender-bending.

\section{Methodological Considerations}

How might the aforementioned movie Two Spirits and the orientation designated by this same term among native Navajos (and indeed among other groups of Native Americans) help us to rethink gender? Young people seem to be taking the initiative on this question today. In a Time Magazine article, author Katy Steinmetz (2017: 53) [3] states it this way: "[T]he big question is whether this is 
just kids experimenting or whether it reflects true variance that has long existed but went unexpressed in past generations. The answer may be both". For one thing, it encourages the researcher temporarily to "deconstruct" the limiting gender categories that we Euro-Americans have in place to describe and developmentally guide people during their life cycle. When undertaking ethnographic fieldwork, the anthropologist has to have a broader conceptual arsenal to apply to the gendered natures of peoples he or she encounters in the fieldwork setting, especially in its initial phases. As the anthropologist gradually becomes more familiar with the emic or "experience-near" categories a particular society employs for designating gender classifications, the anthropologist will likely either modify these provisionally assigned categories or even scrap them altogether: "Some experts say that there is more natural variation than has been widely acknowledged and that terminology is more limited than the sum of human experience" (Steinmetz, K. 2017: 51) [3]. The point is that they may provide a method for an initial attempt at assigning a gender category, subject to change as time and familiarity with the ethnographic community under investigation proceeds. Thus, the methodological usefulness takes precedence here.

The desire to deconstruct gender categories is not some perverse exercise in academic or disciplinary rebellion, but is guided by encouraging a more varied system of choice to help the anthropologist further the trajectory of his or her own research agenda from the very beginning. Such categories are provisional rather than permanent, methodological rather than ontological, subject as they are to reformulation as the anthropologist gathers more reliable data based on ethnographic fieldwork.

In this discussion of cross-cultural gender variance, it is instructive to consider the social reaction to genital ambiguity as a challenging case. Such anatomical indeterminacy tends to provoke one or the other extreme in a polarized response. Either it is roundly condemned as evil, perverse, and/or demonic, inciting violence and the life termination of the source; or, at the opposite end of the spectrum, as very sacred and precious, worthy of veneration, and as a site of transcendent power-a "gift from the gods". In other words, both responsesdisgust and adulation-tap into a supernatural conceptual framework since they evoke a reaction beyond natural expectations.

Although the term third gender appears in the literature, I prefer to reserve this designation to describe the gender status of those possessing sexual anatomical ambiguity while reserving gender variant for those who are biologically and chromosomally male or female and yet do not conform to masculine or feminine heteronormativity.

\section{Gender and Racial Construction}

While deconstructing gender might be discounted by some as no more than an exercise in postmodernism, it nonetheless helps the anthropologist frame gender in ways that reflect ethnographically encountered differences, including my own forty-plus years of immersion in Benedictine monastic community life. 
Henry Louis Gates Jr. in his book Black in Latin America [18] reports that the people of Brazil recognize 134 emic or "experience-near" categories of blackness. Here in the United States, we recognize two, and provisionally three, racial categories: white, black, and (possibly) mulatto. In fact, in most Latin American countries there are many more categories of blackness than here in the U.S. If race can be broken down into so many different categories, could we do the same for gender? Are they analogous? Of course, as a phenotypic designation, registered by sense perception, skin color is visible to all. Gender, however is not always quite as immediately recognizable from one's external appearance and behavior. Still, it seems to me that we could benefit from taking gender from its present binary of masculine and feminine, and thinking about it as a much more complex and differentiated phenomenon. If we could do this, it would provide anthropologists with a more useful methodological tool in their work of accounting for (at least) initial gender classifications in diverse fieldwork settings.

Based on my extended participant observation of these male and female "monastics", I have proposed a common monastic gender status, which stands alongside Western heteronormative cultural models of masculinity and femininity. Given the similarly close interaction of these monastic biological males and females with the transcendent, their common and voluntary renunciation of marriage and procreation, their overlap in dress (the traditional habit), and their shared ascetical lifestyle practices and ritual consecration, such monks and nuns may share a single gender variant status. Even though the popularity of wearing the monastic habit has waxed and waned over the past several decades, especially among female monastics, it is nevertheless a potent marker of monastic identity. The fact that women monastics have largely divested themselves of the habit (or have severely modified it), seems to have less to do with its intrinsic importance as a marker of monastic identity and status, and more to do with a dynamic of disenfranchisement and collective empowerment as well as the adoption of a more active ministerial lifestyle and social outreach. Still, the impact of the traditional garb worn by many monastics should not be underestimated.

[C]lothing infuses the human body with meaning and determines its behavior, often beyond personal preference... Moreover, clothing may not only change our skin and transform our physiology, it may actually define it by controlling our body movements (Hermkens, A-K. 2010: 233) [19].

As Ewert Cousins, author of Christ in the $21^{\text {st }}$ Century, puts it, "[M]onks and nuns... take a radical stand as marginal persons, separating themselves from family and community, stripping themselves of material goods by practicing poverty and withdrawing from the fertility cycles by celibacy-as wandering beggars or as members of monastic communities who share their sense of radicalness" (Cousins, E.H. 1992: 7) [20].

Moreover, mediation is another touchstone among both shamans and monastics as purveyors of the supernatural. (For a bioarcheological perspective on shamanic mediation, see Hollimon, S.E. 1997: 183 [21]). Given their liminal sta- 
tus, Harvey and Wallis remind us that "shamans act as mediators in order to broker harmonious relations between human and other-than-human people" (2007: 252) [4]. Likewise, monastics, in line with their "institutionalized liminality"-as anthropologist Victor Turner puts it-act as mediators for prayer requests in order to broker harmonious relations between human and other-than-human people. Monastics are often targeted for such intervention because of their alleged special intercessory role.

But before succumbing to the opinion that such a gender variant status just "waters down" the masculinity of male monks, or results in some form of androgyny, we must consider the claim of some that the heteronormative European masculine ideal was historically challenged by the masculinity of monks. Ringrose (2003: 20; emphasis added) [22] informs us that "in Late Antiquity, both worldly, procreative men of affairs and ascetic men were biologically or physiologically 'male,' but they were perceived as distinctive gender groups because of their different relationships to sexuality and reproduction". Roughgarden has even gone so far as to claim that "by the beginning of the fifth century, monasticism had become the new Christian masculine ideal" (2004: 362 [23]; see also Kuefler, M. 2009 [24]). Krawiec (2002: 129) [25] discussed this gender variant status by describing monks as metaphorical eunuchs. In pursuing a lifestyle in conformity with the earlier "martyr ideal" - the renunciation of sexuality and procreation and by following a program of strict ascetical discipline culminating in one's total self-donation (in death) to the service of Christ and his Churchmonks came to model a powerful alternative medieval masculine ideal. So pervasive was this new monastic masculine ideal that even women aspired to it in seeking martyrdom as Stephanie Cobb asserts in her book Dying to Be Men: Gender and Language in Early Christian Martyr Texts [26], or in Gillian Cloke's book-title exposition of 'This Female Man of God': Women and Spiritual Power in the Patristic Age, AD 350-450 [27]. Moisés Mayordomo Marin, in his article "Construction of Masculinity in Antiquity and Early Christianity", nicely summarizes this perspective:

Christian masculinity culminates in complete control over one's bodily needs...This anthropological choice paves the way for the latter Christian movement of celibate life. From this perspective, early ascetics and monks were not defective males but, quite to the contrary, hyper-masculine figures, able to control even the most forceful passions (Marin, M.M. 2006: 16) [28].

\section{Rethinking and Revamping Gender Education}

Can such gender variance lead to alternative masculine models than those presented in the movie The Mask You Live In in serving to guide the development of men? Saint John's University, an all-male institute of higher learning in central Minnesota, is one of the very few single-sex institutions of its kind surviving in the United States. Founded over a century and a half ago by Benedictine monks of Saint John's Abbey, the university initiated in 1997 a continuing program of men's spirituality groups, most of which are facilitated by monks who 
model and encourage in college men the development of a heteronormative masculine ideal at odds with a largely self-centered, exploitive, and competitiveconsumerist masculinity that dominates our hyper-capitalist and sexually obsessed society. In their book, Forging the Male Spirit. The Spiritual Lives of American College Men, Longwood, Schipper, and Culbertson stress the participation of monks, a presence I myself can corroborate as a facilitator for several of these groups:

The role of the monks was frequently commented upon by students in the groups. Several students reported that curiosity about the monks was one factor in their decision to participate in the groups. Several toyed with the idea of becoming a monastic, and at the very least, close relationships with the monks in the group generated a new respect for monastic life. Although in the early stages of group development, some of the students looked to the monks as "spirituality experts", this usually shifted over time, so it became more common for students to report their appreciation of the monks' humanity (especially the monks' candor in discussing their own sexuality) as they expressed a deepened interest in monastic life, both of which they would not have had apart from involvement in the spiritualty groups (Longwood, W.M., Schipper, W.C., and Culbertson, P. 2012: 45) [29].

In such gender-suspended contexts, and through the agency of monk facilitators, these groups become experimental laboratories for the safe and confidential exploration of contemporary masculinities-a type of collective "vision quest" in the search for a spiritually integrated masculine identity. Or, as the authors of this book put it:

The exploration and development of spirituality in men's groups can provide an implicit challenge to conventional masculine norms and a crucible for envisioning ways of being male. At the same time, the critical scrutiny of traditional masculinity frees men to enhance their spiritual dimension by challenging the beliefs that would have them regard spirituality as unworthy of "real" men (Longwood, W.M., Schipper, W.C., and Culbertson, P. 2012: 83) [29].

Monks, as agents of a gender variant status, thus stand as potential models of an alternative vision for the contemporary integration of masculinity and spirituality.

\section{Conclusion}

Men's dominant gender-scripted stereotype in the U.S. encourages a hidden dysfunctional emotional life that time and again leads to physical symptoms of stress, substance abuse, and even suicide as portrayed in the movie The Mask You Live In. Cross-cultural anthropological studies of religious specialists reveal gender variant masculinities that accommodate a broader and healthier set of developmental trajectories for attaining manhood. The "institutionalized liminality" of monastic life encourages alternative scripts for young men in contact 
with such religious exemplars. Exposure to monks in an educational institutional setting like the men's spirituality groups at Saint John's University in central Minnesota helps tailor gender education for men along alternate paths, suggesting other spiritually integrated ways of "being a man" that model gender variant masculine models for men to internalize and emulate.

\section{References}

[1] Walker, P.L. and Cook, D.C. (1998) Brief Communication: Gender and Sex: Vive la Difference. American Journal of Physical Anthropology, 106, 255-259. https://doi.org/10.1002/(SICI)1096-8644(199806)106:2<255::AID-AJPA11>3.0.CO;2-\#

[2] Eckert, P. and McConnell-Ginet, S. (2003) Language and Gender. Cambridge University Press, Cambridge. https://doi.org/10.1017/CBO9780511791147

[3] Steinmetz, K. (2017) Infinite Identities. Time Magazine, 48-54.

[4] Harvey, G. and Wallis, R.J. (2007) “Gender", Historical Dictionary of Shamanism. The Scarecrow Press, Lanham, MD, 89-91.

[5] Bacigalupo, A.M. (2007) Shamans of the Foye Tree: Gender, Power, and Healing among Chilean Mapuche. University of Texas Press, Austin.

[6] Agarwal, S.C. (2012) The Past of Sex, Gender, and Health: Bioarchaeology of the Aging Skeleton. American Anthropologist, 114, 322-335. https://doi.org/10.1111/j.1548-1433.2012.01428.x

[7] Nanda, S. (2000) Gender Diversity: Crosscultural Variations. Waveland Press, Prospect Heights, Illinois.

[8] Lang, S. (1998) Men as Women, Women as Men: Changing Gender in Native American Cultures. University of Texas Press, Austin.

[9] Hoebel, E.A. (1978) The Cheyennes: Indians of the Great Plains. Holt, Rinehart and Winston, New York.

[10] Sheldrake, P. (2001) Human Identity and the Particularity of Place. Spiritus, 1, 4364. https://doi.org/10.1353/scs.2001.0018

[11] Czaplicka, M. (1914) Aboriginal Siberia: A Study in Social Anthropology. Oxford University Press, Oxford.

[12] Balzer, M.M. (1996) Sacred Genders in Siberia: Shamans, Bear Festivals, and Androgyny. In: Ramet, S.P., Ed., Gender Reversals and Gender Cultures: Anthropological and Historical Perspectives, Routledge, London and New York, 164-182.

[13] Horswell, M.J. (2005) Decolonizing the Sodomite: Queer Tropes of Sexuality in Colonial Andean Culture. University of Texas Press, Austin.

[14] Launderville, D. (2010) Celibacy in the Ancient World: Its Ideal and Practice in Pre-Hellenistic Israel, Mesopotamia, and Greece. Liturgical Press, Collegeville, MN.

[15] Peletz, M.G. (2006) Transgenderism and Gender Pluralism in Southeast Asia since Early Modern Times. Current Anthropology, 47, 309-340.

https://doi.org/10.1086/498947

[16] Peletz, M.G. (2009) Gender Pluralism: Southeast Asia Since Early Modern Times. Routledge, New York.

[17] Peled, I. (2016) Masculinities and Third Gender: The Origins and Nature of an Institutionalized Gender Otherness in the Ancient Near East. Ugarit-Verlag-Buchund Medienhandel Ltd., Münster, Germany.

[18] Gates, H.L. (2011) Black in Latin America. New York University Press, New York.

[19] Hermkens, A.-K. (2010) Clothing as Embodied Experience or Belief. In: Morgan, 
D., Ed., Religion and Material Culture: The Matter of Belief, Routledge, London and New York, 231-246.

[20] Cousins, E.H. (1992) Christ of the 21st Century. Element, Rockport, MA.

[21] Hollimon, S.E. (1997) The Third Gender in Native California: Two-Spirit Undertakers among the Chumash and Their Neighbors. In: Claassen, C. and Joyce, R.A., Eds., Women in Prehistory. North America and Mesoamerica, University of Pennsylvania Press, Philadelphia, 173-188.

[22] Ringrose, K.M. (2003) The Perfect Servant: Eunuchs and the Social Construction of Gender in Byzantium. The University of Chicago Press, Chicago, London. https://doi.org/10.7208/chicago/9780226720166.001.0001

[23] Roughgarden, J. (2004) Evolution's Rainbow: Diversity, Gender and Sexuality in Nature and People. University of California Press, Berkeley and Los Angeles.

[24] Kuefler, M. (2009) Soldiers of Christ: Christian Masculinity and Militarism in Late Antiquity. In: Krondorfer, B., Ed., Men and Masculinities in Christianity and Judaism: A Critical Reader, SCM Press, London, 239-258.

[25] Krawiec, R. (2002) Shenoute and the Women of the White Monastery: Egyptian Monasticism in Late Antiquity. Oxford University Press, New York. https://doi.org/10.1093/0195129431.001.0001

[26] Cobb, L.S. (2008) Dying to Be Men: Gender and Language in Early Christian Martyr Texts. Columbia University Press, New York. https://doi.org/10.7312/cobb14498

[27] Cloke, G. (1995) “This Female Man of God": Women and Spiritual Power in the Patristic Age, AD 350-450. Routledge, London and New York. https://doi.org/10.4324/9780203422540

[28] Marin, M.M. (2006) Construction of Masculinity in Antiquity and Early Christianity. Lectio Difficilior, February, 1-33.

[29] Longwood, W.M., Schipper, W.C. and Culbertson, P. (2012) Forging the Male Spirit: The Spiritual Lives of American College Men. Wipf and Stock, Eugene, OR.

\section{Scientific Research Publishing}

Submit or recommend next manuscript to SCIRP and we will provide best service for you:

Accepting pre-submission inquiries through Email, Facebook, LinkedIn, Twitter, etc. A wide selection of journals (inclusive of 9 subjects, more than 200 journals)

Providing 24-hour high-quality service

User-friendly online submission system

Fair and swift peer-review system

Efficient typesetting and proofreading procedure

Display of the result of downloads and visits, as well as the number of cited articles

Maximum dissemination of your research work

Submit your manuscript at: http://papersubmission.scirp.org/

Or contact jss@scirp.org 